\title{
Path Choices of Modern Service Industry Development in Jilin Province
}

\author{
Huijun Li \\ School of Economics, Changchun Institute of Finance and Economics, Changchun, Jilin 130122 \\ E-mail:77703992@qq.com
}

Keywords: modern service industry, problems, path choices

\begin{abstract}
In recent years, the contribution rate of service industry to economic growth in Jilin Province has been continuously increasing. In 2017, the proportion of service industry in GDP in Jilin Province was lower than that in the secondary industry. There is still a big gap compared with the overall level of the whole country (the proportion of tertiary industry in China was 51.6\% in 2017). At present, the service industry should emphasize on industry structure, product quality, and industry centralization. Its development will be more rapidly than the first industry and the second industry. In the future, the service industry will service for other industries indeed and promote the economic level of the whole province.
\end{abstract}

At present, China's economic development has shifted from high-speed growth to medium-high-speed growth which is the "new normal economy". And our reform has shifted from demand-side to supply-side. That is to say, economic reform should take "supply-side structural reform" as the main line. This reform not only brings challenges but also opportunities for the development of service industry in Jilin Province.

\section{Modern Service Industry}

In our country, the concept of modern service industry was first put forward in the report of the 15th National Congress of the CPC in September 1997. In 2000, the Central Economic Work Conference proposed that "we should not only transform and improve the traditional service industry, but also develop new service industries such as tourism, information, accounting, consultation and legal services". On February 22, 2012, Document No. 70 issued by the Ministry of Science and Technology pointed out that modern service industry is a service industry based on modern science and technology, especially information and network technology, and built on new business models, service modes and management methods. It includes not only the emerging service industry with the development of technology, but also the transformation and promotion of traditional service industry with modern technology. The development of modern service industry essentially comes from the needs of social progress, economic development and specialization of social division of labor. It has the characteristics of high intensity of intellectual factors, high added value of output, less consumption of resources and less environmental pollution. Its essence is to realize the modernization of service industry. Therefore, modern service industry is the extension of 
traditional service industry. Under the background of informationization, intellectualization and networking, it represents the tertiary industry, so the data of modern service industry in this paper refers to the data of the tertiary industry.

\section{Development Status of Modern Service Industry in Jilin Province}

\subsection{Overall development of service industry in Jilin Province}

In 2017, the GDP of Jilin Province reached 1528.894 billion yuan, an increase of 5.3\% compared with the same period last year in terms of comparable prices. The added value of the primary industry was 142.921 billion yuan, an increase of 3.3\%, the added value of the secondary industry was 701.285 billion yuan, an increase of $39 \%$, and the added value of the tertiary industry was 684.688 billion yuan, an increase of $75 \%$. The proportion of the three industries is 9.3:45.9:44.8, and their contribution to economic growth is $6.9 \%, 36.9 \%$ and $56.2 \%$.

From the overall data, the development of service industry in Jilin Province has the following characteristics:

\subsubsection{The service industry in Jilin Province is developing at the top of the three major industries.}

In terms of industrial added value, the industrial added value of service industry increased steadily, reaching 684.688 billion yuan in 2017. In terms of the growth rate of the same year, the service industry in Jilin Province grew at a rate of 7.5\% in 2017, which is not only the first of the three major industries, but also 2.2 percentage points higher than the economic growth rate of the whole province (5.3\%).

\subsubsection{The contribution rate of service industry to economic development in Jilin Province has become increasingly prominent.}

In terms of the proportion of three industries to GDP, the proportion of service industry to GDP was $44.8 \%$ in 2017 , and the contribution rate of economy reached $56.2 \%$, far exceeding that of secondary industry.

\subsection{Internal Development of Service Industry in Jilin Province}

According to the statistical scope of Jilin Province's service industry, it mainly includes wholesale and retail trade, public management, social security and social organizations, transportation, storage and postal industry, financial industry, real estate industry, education, accommodation and catering industry, information transmission, software and information technology services, residential services, repair and other services. Industry, leasing and business services, health and social work, scientific research and technology services, culture, sports and entertainment, water conservancy, environment and public facilities management, a total of 14 categories.

\subsubsection{Services, such as retail, account for a large proportion of growth.}

The value added of wholesale and retail trade in 2016 was 12.0314 billion yuan, accounting for $19.2 \%$, which ranked first in all sectors of service industry; the value added of transportation, warehousing and postal industry in 2016 was 55.838 billion yuan, accounting for 8.9\%; the value added of accommodation and catering industry was 36.876 billion yuan, accounting for $5.9 \%$. 


\subsubsection{The financial sector is growing fast.}

The financial industry has grown rapidly. In 2016, the added value of the financial industry was 65.955 billion yuan, accounting for $10.5 \%$ of the service industry, and the growth rate was relatively fast. The value-added of information transmission, software and information technology services, scientific research, culture and sports developed slowly.

\section{Problems in the Development of Modern Service Industry in Jilin Province}

3.1 In terms of the total amount, although the service industry is developing rapidly, the total amount is not large and its share in GDP is still on the low side.

In recent two years, the development speed of service industry in the whole province has been faster than that of the second industry, and also higher than the GDP growth of the whole province. However, the total amount of service industry still lags behind that of the second industry and is lower than the average level of the whole country. This shows that the development of service industry in our province lags behind, but at the same time it also contains tremendous development space and potential.

\subsection{From the structural point of view, the service industry structure is not good,}

Business, catering and other services account for a large proportion, financial, insurance, information and software industries and other services account for a low proportion, with fewer professional skilled personnel. From the current situation of service industry in Jilin Province, we can see that the proportion of service industry with high added value, informatization and knowledge-based is low, the quality of personnel engaged in modern service industry is uneven, and the number of people who have mastered professional knowledge and skills is small.

\subsection{From the supply point of view, the number of service enterprises is large, but the number of brand enterprises is small.}

The degree of homogeneity of products is high, and innovation is not strong. In the same industry and field, the products managed by service enterprises have little difference and high homogeneity. Because of the limited R\&D investment and the low degree of cluster, enterprises have not strong innovation ability, low added value of their products, and often carry out price wars among enterprises, vicious competition and unfair competition occur frequently.

3.4 From the point of view of scientific research transformation, there are many employees in education, scientific research and technical services, but the added value is not high.

Jilin Province is a large province of science and education, with 58 ordinary colleges and universities and many research institutes. However, influenced by concepts, entrepreneurial environment and government policies, scientific researchers have been keeping the "golden rice bowl" for a long time, lacking entrepreneurial enthusiasm, and low conversion rate of scientific research results, resulting in low output value and insufficient economic pull.

3.5 From the perspective of openness, the export-oriented degree of service enterprises in Jilin Province is low.

In terms of the number of enterprises, the service industry enterprises in Jilin Province are 
affected by the social reform, and the degree of opening to the outside world is very low.

\section{Path Choices of Modern Service Industry Development in Jilin Province}

\subsection{The service industry should maintain a certain growth rate.}

Although the development speed of service industry in Jilin Province has been greatly improved, there is still a big gap compared with the national average level and other provinces, which provides more urgent requirements for the development of service industry. On February 14, 2016, the provincial Conference on the development of service industry held in Jilin Province put forward: "In the next five years, the added value of service industry should maintain an average annual growth rate of more than $10 \%$, so that service industry will become the main driving force for economic growth. The proportion of added value of service industry to GDP will reach more than $45 \%$ in 2020, striving to spend about 10 years. Services account for more than industry, completely reversing the face of industry as a pillar of optimism. High-speed growth of service industry is not only the requirement of productivity development, but also the driving force of rapid progress in our province. Maintaining a certain growth rate is the premise and key of service industry development.

4.2 Foster growth poles centered around Changchun, promote the development of surrounding cities and promote the economic upgrading of the whole province.

Changchun City is the capital of Jilin Province and the only sub-provincial city with superior geographical position. It is in the forefront of the province in terms of utilizing foreign direct investment, receiving domestic and foreign tourists, attracting employment and so on. Changchun has abundant human resources, material conditions and the inclination and support of national policies. If Changchun is taken as the development center, and through exerting its own advantages and cluster effect, it will radiate and drive the development of surrounding cities, and ultimately promote the overall upgrading of Jilin Province's service industry.

\subsection{Take Hunchun International Cooperation Demonstration Zone and Hachang City Group as development opportunities to improve the aggregation, openness and competitiveness of service industry enterprises.}

Both Hunchun International Cooperation Demonstration Zone and Hachang City Cluster provide a good opportunity for the development of service industry in Jilin Province. It is an important way to improve the openness and competitiveness of service industry in Jilin Province. Jilin Province's service industry should seize this development opportunity, fully develop exchanges with other provinces and municipalities through information technology and network resources, form clusters, cultivate well-known enterprises and brands in enterprises of similar products, avoid disorderly competition and vicious competition, and build up a batch of enterprises with distinct characteristics and strong competition in the province. Strength of modern service industry agglomeration area, improve the quality and competitiveness of service enterprises.

\subsection{Strengthen policy support, promote the transformation of scientific research achievements, and increase support for emerging service industries.}

Jilin Province is a big province of science and education. We should seize this rich educational resources, boldly encourage cooperation among universities, scientific research institutes, vocational schools and related enterprises, promote the transformation of scientific research 
achievements, and train a group of skilled talents with both theoretical and practical expertise. By optimizing the development environment, strengthening factor guarantee and strengthening financial and taxation support, we can create a strong foundation for the development of new service industries in Jilin Province. We should focus on the development of modern finance, modern logistics, modern commerce, information services, tourism and Exhibition services, vigorously develop e-commerce, so as to make the service industry in Jilin Province informatization, technological, networked, intellectualized and high value-added.

\subsection{Service enterprises should adapt themselves to the structural reform on the supply side and constantly improve and upgrade.}

The service industry enterprises should rely on the Internet and information technology to promote their own upgrading and provide higher quality services for other types of enterprises on the basis of the needs arising from the reform. Through participating in the cooperation of enterprises in science and technology parks, software parks and other parks, as well as regional cooperation with Hachang Great Wall Group, Changjitu and foreign enterprises. Service enterprises should continuously improve their innovation ability and competitive power and make their products more value-added and improve their products in the domestic and international markets.

\section{Acknowledgment}

Fund Project: Phased Research Achievements of the Social Science Project of the 13th Five-Year Plan of Jilin Provincial Department of Education "Research on the Current Situation and the Strategies of Transformation and Upgrading of Service Industry Development of Jilin Province under the Conditions of Supply-side Structural Reform" (Contract No. JJKH20171016SK)

\section{References}

[1] Statistical Bulletin of National Economic and Social Development of Jilin Province 2017 [EB/OL]. Jilin Statistical Information Network, 2018-3-28.

[2] Jilin Statistical Bureau. Jilin Statistical Yearbook (2017) [M]. Beijing: China Statistical Publishing House, 2017.

[3] Jilin Province: Promoting the development of service industry and creating a new engine for the revitalization of Northeast China [EB/OL]. Fenghuang Net, 2016-2-15.

[4] Harbin Great Wall City Group has won four major positioning [EB/OL]. Fenghuang Net, 2016-3-4.

[5] Researchers in Jilin went to Shanghai to start their own businesses [N]. City Evening News, 2016-3-24.

[6] Interpretation of "Some Implementing Opinions of Changchun Municipal People's Government of Changchun Municipal Committee of the Communist Party of China on Promoting the Accelerated Development of Service Industry" [EB/OL]. Changchun Municipal People's Government website, 2016-4-1.

[7] Lina Zhang and Shu Zhou. Problems and Countermeasures of modern service industry development in Jilin Province [J]. Economic Vertical and horizontal, 2009, (05).

[8] Hongqiao Cui,Songdong Shen. Research on the coordinated development of urbanization and service industry in Jilin Province [J]. Longitudinal and horizontal economy, 2014, (01).

[9] Wenxiu Li etc. Convergence or Agglomeration of China's Interregional Service Industry Development: A Study Based on the Panel Data of Investment Efficiency of Provincial Sub-sectors [J]. Macroeconomic Research, 2012 (08). 